\title{
Treatment of persistent pain from torture: review and commentary
}

Amanda C de C Williams - corresponding author

Reader in Clinical Health Psychology

Research Department of Clinical, Educational and Health Psychology

University College London

Gower Street, London WC1E 6BT, UK

$+44(0) 2076791608$

amanda.williams@ucl.ac.uk

Kirstine Amris,

Consultant Rheumatologist

University Hospital of Copenhagen, Bispebjerg and Fredriksberg,

Parker Instituttet og

Videncenter for Reumatologi og Rygsygdomme

Nordre Fasanvej 57

2000 Frederiksberg

Copenhagen

Tel: +4538166240

Kirstine.Amris@regionh.dk

\section{Abstract}

Torture and the conditions under which it is inflicted often leave persistent painful disorders.

Because there may be no lasting signs, persistent pain is often misconceived as a somatic

representation of psychological distress, also common after torture. This serious failure to

understand the nature of persistent pain means that pain is largely overlooked and untreated in torture survivors. We carried out a systematic review on treatments for pain from torture, but found very little, and even less informed by current understanding and evidence. We discuss this in the context of treating pain in the context of psychological distress and of the broader problems faced by the refugee and torture survivor that may take priority over pain. We propose clinical and research implications for this neglected field.

\section{Keywords}

Chronic pain; PTSD; pain assessment; rehabilitation; human rights. 
Pain is a defining feature of torture, for which we take the World Medical Association (2006) definition of "the deliberate, systematic or wanton infliction of physical or mental suffering by one or more persons acting alone or on the orders of any authority, to force another person to yield information, to make a confession, or for any other reason." It often persists after torture, but such pain is widely misunderstood and dismissed as a nonspecific symptom of post-traumatic stress or depression (also very common), both in specialist psychologically-oriented torture services and in mainstream health systems. The effect of this is that, although multidisciplinary team contribution to psychosocial rehabilitation has long been the gold standard in torture services (Quiroga and Jaranson 2011), pain continues to be underassessed and undertreated, and there remains no consensus on how to understand it. This is an appalling disservice to already severely disadvantaged people. Rehabilitation is identified as a right in the UN Convention on Torture, aiming to restore as far as possible the health and capacity for full participation in society of torture survivors. This implies specialist services, preferably integrated, and appropriate and accessible, but nowhere in the world do such services exist. That is the explicit context for our review here of pain after torture, and of its treatment. We first describe persistent (chronic) pain and pain mechanisms in general, and then from torture; we summarise issues of assessment and recognition in clinical settings; we address treatment and rehabilitation of acute and chronic pain after torture, including the results from systematic review of pain treatment after torture; we place these findings in the context of psychological treatments for torture survivors, and then in the broader context of problems facing the survivor. We close with clinical and research implications.

\section{Pain}

The standard definition of pain is that it is "An unpleasant sensory and emotional experience associated with actual or potential tissue damage, or described in terms of such damage" (Merskey and Bogduk 1994), but an update has been proposed: "Pain is a distressing experience associated with actual or potential tissue damage with sensory, emotional, cognitive and social components" (Williams and Craig 2016). Chronic (persistent) pain is commonly defined as pain that lasts for more than 3 months and is not attributable to a degenerative or progressive condition; that is, it has no tissue-based explanation (Wall 
1999; Woolf 2010). Both the foregoing definitions emphasise the breadth of the experience of pain and its far-reaching effects on the individual.

Within clinical and research fields of pain, the biopsychosocial model of pain (Turk and Okifuji 2002) dominates. It emphasises the interconnectedness of the biological, brain, periphery and organs; the psychological, both experiential and behavioural and with increasing contributions from neuroscience; and the social context in which pain occurs and is expressed. The model emphasises distinctions from what is often referred to as a 'biomedical' model, in which the report or behaviour indicating pain prompts investigation for an underlying lesion or pathology in peripheral tissues, in the absence of which the report or behaviour is suspect. Yet there is no reason why expressed pain should serve as an index of extent of tissue damage or seriousness of pathology: acute pain prompts selfprotective behaviour and needs only to be enough to promote survival (Williams 2002; Williams 2016); and expression of pain is modulated by many factors (Hadjistavropoulos et al. 2011). There are many neurophysiological mechanisms, some generated by inflammatory or hormonal processes that generate pain in the absence of pathology or lesions (Woolf 2010). It has been suggested that the remarkable similarities of processes that occur in the central nervous system, and particularly the brain, in persistent pain, whether there is diagnosed or identifiable cause or not, suggest that we might consider chronic pain to be a disease in its own right (Tracey and Bushnell 2009).

Beyond the field of pain studies and their application, pain is commonly conceptualised as a symptom of a verifiable medical problem or, if none can be found, as a manifestation of a psychological process variously called 'psychosomatic disorder', 'somatisation', or similar (Williams and Johnson 2011). These models apply poorly to pain (Crombez et al. 2009; Merskey 2009), taking no account of multiple pain mechanisms of amplification and (failure of) inhibition that play a crucial part in modulating pain experience (Wall 1999; Woolf 2010; Tracey and Bushnell 2009; Williams and Johnson 2011), acute or chronic. Despite their conceptual and empirical weakness, they are widely invoked in treatment and are further discussed below.

\section{Pain from torture}

Estimation of the prevalence of post-torture pain in non-selected populations, and knowledge about the natural course of pain, are not available. Data exist mainly from 
descriptive studies conducted in selected populations, applying different methodologies and not specifically focused on questions of pain. Nevertheless, studies of torture survivors set in specialised documentation and/or treatment centres are consistent in reporting a high prevalence of persistent pain, with overall estimates as high as $83 \%$ (Olsen, Montgomery, Carlsson and Foldspang 2006; Olsen, Montgomery, Bøjholm and Foldspang 2006; Williams, Peña and Rice 2010).

Commonest is headache (Amris 2005; Musisi et al. 2000) and musculoskeletal pain; pain related to the spine (Musisi et al. 2000; Dülgeroglu 2000; Rasmussen 1990), joint pain (Moisander and Edston 2003), foot pain ( Moisander and Edston 2003; Edston 2005; Olsen et al. 2007) and pelvic pain (Musisi et al. 2000). Widespread pain is frequent (Edston et al. 2000). Although one study comparing survivors seen within two weeks of torture with those seen later indicated some spontaneous resolution of pain (Dülgeroglu 2000), a follow-up study of survivors in Denmark showed increased prevalence of chronic pain over the intervening 10 years (Olsen et al. 2007).

Several forms of physical torture (e.g. beatings, strapping, suspension by the extremities, forced positions, electrical torture) may cause injuries in the musculoskeletal system, mainly soft tissue lesions, but the best described pain problems arising from specific torture methods are foot pain from falanga (beating the soles of the feet) and shoulder and upper limb pain from suspension by the arms.

Falanga is commonly reported by torture survivors (Edston et al. 2009). The immediate effect of falanga is bleeding and oedema in the soft tissues and severe pain. Swelling of the feet, haematomas in the soles and various degrees of skin lesions are typical and diagnostic findings in the acute phase (Bro-Rasmussen and Rasmussen 1978). Extensive ulcerations and fractures are uncommon. Long term, falanga leaves no specific gross signs, but is characterised by a neuropathic burning and stinging pain in the sole; sensory and autonomic changes; a dull deep pain in the feet on weight bearing, spreading up the lower leg with walking and eased by rest (Edston 2009; Prip and Persson 2008; Prip et al. 2011); and distorted gait with abnormal unwinding of the foot and short walking distance. All these can seriously affect daily activities (Prip, Persson, and Sjolund 2011). Scars and/or pigmentations in the soles may be evident (Edston 2009), and reduced elasticity in the foot pads on palpation, loosening of the skin, soreness and coating of the plantar fascia, and 
sensory disturbances in the soles appear to be characteristic although not pathognomonic (Amris, Torp-Pedersen and Rasmussen 2009). MRI (Savnik et al. 2000) and Doppler examination (Torp-Pedersen et al 2009) have identified thickening of the plantar aponeurosis, but not the muscle compartment syndrome anticipated or thinning of the heel pad. Quantitative sensory testing suggests some small fibre neuropathy (Prip, Persson, and Sjolund, "Pain when walking", 2012; Prip, Persson, and Sjolund, "Sensory functions", 2012). Suspension by the arms, especially with the arms tied behind the back, the shoulder joint maximally extended and inwardly rotated (also unjustly called "Palestinian hanging"), strains and injures the shoulder joint and surrounding soft tissues. Symptoms in the acute phase are severe pain in the neck and shoulder girdle and loss of shoulder function accompanied by neurological symptoms in the upper extremities; irradiating pain and sensory disturbances. Dislocations of the shoulder joints occur, but are uncommon (Dülgeroglu 2000). A typical long-term presentation is of pain in the shoulder, upper arm, and neck; weakness and fatigue in the arm; sensory changes; restricted movement and a sensation of looseness and instability in the shoulder joint. Clinical findings are mostly not specific; a few systematic studies of the possible mechanisms underlying long-term pain and associated symptoms have proposed overload injuries of the shoulder joint, such as injuries of the glenoid labrum, joint capsule and ligaments; and partial lesions of the brachial plexus (Rasmussen et al. 2005).

There are rather less well-developed associations of pelvic pain in women with sexual assault and sexual torture (Rasmussen et al. 2005; Williams et al. 2010), and of anal pain and urological problems in men after sexual torture (Norredam et al. 2005; Williams et al. 2010). Again, these pains are located in soft tissue with little or no findings on examination or scanning, but they are entirely consistent with phenomenology of pelvic pain in the general population (Engeler et al. 2015).

\section{Pain mechanisms in chronic post-torture pain}

The concepts of pain syndromes evolving over time, predicted by the severity, extent, and repetition of the original trauma, are presumed to apply to post-torture pain, but studies are lacking. Most literature on long-term consequences of torture is descriptive, listing symptoms or clusters of symptoms, so the aetiology and pathogenesis of the persistent musculoskeletal complaints are not known. Careful documentation and studies of survivors 
are however beginning to establish connections between some forms of torture and persistent pain, better described by mechanism than by site. Mechanism-based pain classification refers to the classification of pain according to pathophysiological mechanisms presumed to be responsible for its initiation and/or maintenance. Nociceptive pain (pain related to tissue injury and inflammation), neuropathic pain (pain related to injury or disease in the somatosensory system) and centrally mediated pain (pain related to augmented central pain processing) have been suggested as clinically meaningful mechanism-based classifications of musculoskeletal pain.

In the torture survivor, pain originating in peripheral nociceptors may be caused by: 1) permanent injury in the musculoskeletal system, such as lesion of the shoulder joint after suspension by the upper extremities, lesion of the knees caused by direct blows or forced prolonged knee-loading positions, or lesion of plantar structures after falanga; and/or 2) strain in the musculoskeletal system secondary to overload and disuse due, for instance, to joint dysfunction and compensatory altered posture, movement or gait.

Traumatic nerve lesion caused by blows, strangulation, traction, and other forces are probably common in survivors of torture, and neuropathic pain therefore a likely pain mechanism. Neuropathic pain syndromes have been described in survivors of torture based on the clinical presentation: neuropathic pain due to partial lesion of the brachial plexus after suspension by the upper extremities; partial lesion of the lumbosacral plexus after suspension by the lower extremities; segmental, radiating pain after forced, back-loading positions; trigeminal neuralgia after head trauma; and peripheral neuropathy after tight binding of wrists or ankles (Rasmussen et al. 2005; Moreno and Grodin 2002; Thomsen, Eriksen, and Schmidt-Nielsen 2000; Williams and Amris 2007).

Central sensitisation and dysfunction of descending pain modulating systems are implicated in several chronic muscular pain syndromes from torture: regional or widespread pain often associated with poor sleep, fatigue, cognitive impairment, headache, and visceral symptoms, variously diagnosed in other settings as chronic widespread pain (CWP), fibromyalgia, and polysymptomatic functional syndromes. Unsuccessful attempts to match subjective pain reports to objective findings, in the context of unfamiliarity with chronic pain mechanisms among health care professionals, and evident psychological distress in the survivor, are used to support psychosomatic theories of pain, even when torture has been 
disclosed and documented. Evidence supports understanding this type of pain in terms of changes in pain signalling in the central nervous system in the context of prolonged high levels of pain and distress (Amris 2005; Amris and Williams 2007). Further head injury of the sort incurred by many torture survivors is an independent risk for the development of chronic pain elsewhere in the body (Nampiaparampil 2008).

\section{Assessment and treatment}

\section{Good practice in clinical assessment}

Clinical assessment of torture survivors can be done: 1 ) in order to document findings consistent with allegations of torture and 2) for the purpose of intervention. In documenting torture, the focus will be on the description of symptoms and signs, which provide evidence to support the account of torture. Expert documentation of torture is well established in medical work against torture and international guidelines on assessment of torture survivors for medico-legal purposes are described in the "Manual on the Effective Investigation and Documentation of Torture and other Cruel, Inhuman or Degrading Treatment or Punishment" (the Istanbul Protocol), drafted in 1999 (United Nations 2001). It should be stressed, though, that few symptoms/symptom constellations can be related uniquely to the use of specific torture methods. Physical findings months or years after torture are generally non-specific and cannot, standing on their own, document exposure to torture.

When the assessment is for the purpose of intervention and rehabilitation, a standard pain assessment, with thorough examination of the musculoskeletal system and neurological evaluation, is essential to identify treatable disorders and where possible to identify what mechanisms are generating or maintaining pain. Patients with chronic pain rely on the clinician to identify pain mechanisms based on identifiable and discriminatory patterns of symptoms and signs assumed to reflect the underlying pathophysiology. Proper assessment of the musculoskeletal system in torture survivors is time-consuming, as most have been exposed to multiple forms of torture and may present with numerous pains and physical impairments. Knowledge of common methods of torture and of the likely mechanisms by which they produce pain is required for a systematic and effective examination. The pain history should include specific information about applied torture methods and onset of pain 
in relation to these; this information helps the clinician to ascertain possible damage to the musculoskeletal and peripheral nervous system and assess potential pain mechanisms. It is very common, however, for the clinician to be unable to identify any specific peripheral tissue damage inflicted in torture that 'explains' the pain, nor any clear relationships between tortures endured and current pain and related symptoms. Widespread pain, indicative of aberrant central pain processing, is very common and associated with stress, sleep disturbance, psychological distress, and other relevant factors (Arguelles et al. 2006) from the survivor's torture history. Additionally, various factors decrease the quality of the history: periods of unconsciousness; impaired memory; shame at disclosure, for instance, of sexual assaults.

Most torture survivors attribute the start of the pain to the torture, and describe that pain as continuing, albeit usually with varying intensity; others describe remission of initial pain only for it to reappear later at high intensity and with a different quality. It is also important to ask patients about their beliefs about the pain, about damage done, and about the causes and implications of their pain. In many cultures, pain is assumed to signal ongoing damage, and an explanation of mechanisms of persistent pain without damage enables patients to reframe pessimistic beliefs about the possibility of improved function, and to discuss changes in behaviour that will promote rehabilitation.

\section{Recognising survivors of torture in health care settings; special considerations}

The obligation for health professionals to know about torture, its methods, health-related consequences, and possibilities for rehabilitation, has been signified in various declarations, but there remains a large gap in knowledge among most health care providers. As a consequence, the traumatic background of torture survivors referred to mainstream health care is often missed (Eisenmann et al. 2000; Crosby et al. 2006). The identification of torture survivors in the clinical setting relies mainly on clinicians, since torture survivors are often reluctant to reveal their traumatic background, but the health professional may hesitate to ask because of uncertainty about the torture survivors' reaction or for other reasons. The unfortunate situation, where both the health professional and the torture survivor are silent about the trauma, may lead to a failure to make sense of the patient's presentation, lack of understanding, misguided interventions and negative treatment outcomes. It is therefore imperative, when good contact has been established, to ask openly about a prior history of 
physical or psychological assaults, including the use of specific torture methods. The disclosure is often a relief for the survivor and taken as a sign that he or she is likely to be believed and treated with concern.

Special considerations in the clinical encounter with the torture survivor are necessary. Some torture survivors have experienced the involvement of health professionals, for example prison doctors, in the torture situation; survivors' distrust may extend to health professionals in general (Amris et al. 2007; Rasmussen 1990, 1991; O'Connor 2009; Sonntag 2008; Vesti 1990). Particular attention should be paid to the fact that the torture survivor may have been forcibly medicated in the past. Health professionals must therefore make sure to gain the survivor's confidence. Professional interpreters are often required, and are preferable to family members or untrained health care staff; the neutrality and professional confidentiality of the interpreter are crucial and should be explained to the torture survivor. Procedures that are reminiscent of torture, such as those involving electrical equipment or scans performed in closed tubes, should be carefully explained and can in most instances be completed. Flashbacks are intrusive memories that result in re-experiencing a traumatic event, sometimes to the extent of losing contact with present reality, and can be provoked by events reminiscent of the torture situation: medical equipment, uniforms, waiting, waking from unconsciousness (e.g. anaesthesia), and other events and cues. The risk of flashbacks is minimised by a calm atmosphere, detailed explanations of planned procedures, obtaining fully informed consent, and facilitating the patient's control over procedures.

\section{Treating acute pain}

It is relatively rare for injuries and pain from recent torture to be written up in the academic literature, but they are certainly documented for legal and political purposes. The associated acute signs and symptoms are similar to those following other types of acute traumas causing lesions in soft tissues, joints and the skeleton. While there is no a priori reason why evidence-based treatments for acute pain should not be offered with expectation of benefit to survivors of torture (subject to acceptability of methods which risk causing flashbacks), considerable care should be taken not to underestimate pain and the likelihood of its becoming chronic. Most research, non-human animal or human, on pain from injury or disease takes place in conditions of good nutrition and hygiene, minimal exposure to pain before attempted analgesia, and with attempts to minimise stress. Pain is inflicted in torture 
often under conditions of extreme and prolonged stress that may have profound effects on neurophysiology and the processing of pain.

The main predictors of acute pain persisting beyond resolution of the cause, if any, are the intensity of pain and of distress (Linton 2000); with chronicity, processing of all pain increasingly involves the limbic system (Apkarian, Hashmi and Baliki 2011), and the emotional component of pain identified in the definitions cannot be ignored. Anxiety about the cause of pain, about its persistence, and about a future disabled by pain all impinge on the experience and capacity to cope with it (Lumley et al. 2011), as do low mood, loss of valued activities and a projected future, and lack of motivation. The torture survivor who is a refugee and asylum seeker has additional problems which complicate presentation, assessment and treatment: uncertainty about civil status; unstable accommodation or homelessness; isolation from family, community and even others speaking the same language; anxiety about family and friends in the country s/he fled; poverty; racism and hostility in the host society (Gorst-Unsworth and Goldenberg 1998). Detention in the host country is associated with serious deterioration in mental health (Steel et al. 2006) and an increase in pain and associated disability has also been reported in a recent Danish study of traumatised asylum seekers assessed at arrival and 10 months later (Morville et al. 2014).

\section{Living with chronic pain}

Chronic or persistent pain has serious adverse consequences on the individual, as described above, and on his or her capacity to continue to meet the demands of everyday life, many of which exacerbate the pain, and which the individual may believe risk permanent damage. Chronic pain also accounts for considerable demands on primary, secondary and specialist health care, some of which treatments may be harmful. Patients' hopes of relief are repeatedly raised and dashed, and they are rarely given guidance on how to recover some quality of life despite pain. There are no highly effective treatments. Untreated, people with chronic pain tend to rely largely on analgesics and rest, perhaps motivated by anxiety as much as by pain (Vlaeyen and Linton 2012), but these strategies are associated with greater disability and more use of health care for pain (Blyth et al. 2005).

A conventional focus on pain would, after excluding treatable disease as the cause of pain, recommend judicious use of analgesic methods, pharmacological and physical, before or alongside rehabilitative pain management aimed at improving quality of life despite ongoing 
pain, albeit with better control of pain in some cases (see Recommendations for Pain Treatment Services, IASP). Pain management consists of providing information about chronic pain; physical exercise and recovery of valued activities, by gradual steps; cognitive therapeutic methods to intervene in unhelpful beliefs and thinking processes around pain and in low mood; encouraging changes in behaviour in the person with pain and those around him or her to maximise autonomy and confidence in managing the pain (Williams, Eccleston and Morley 2012; Eccleston et al. 2013). Pain management of this type, using psychological foundations and methods, produces small but robust benefits for disability and mood (Williams, Eccleston and Morley 2012), and reduce health care use (Pike, Hearn and Williams 2016); for disability, gains are similar to those obtained from physical exercise treatment or from effective analgesia (Eccleston, Morley and Williams 2013). However, face to face treatment is only available to a small number of those with chronic pain, and in a few wealthier countries. There are several internet and printed self-treatment courses, but none has been adequately evaluated: most have a very low rate of completion, particularly among those who are depressed, and benefits are marginal (Heapy et al. 2015).

\section{Rehabilitation after torture: psychological problems}

In their review of chronic pain in torture survivors, Carinci, Mehta and Christo (2010) refer to restrictions of activity attributable to "fear and confusion" about why the pain persists, and recommend multidisciplinary rehabilitation of the sort described above. We made similar recommendations (Amris and Williams 2007), as others doubtless have done before and since. Yet the research literature on rehabilitation for survivors of torture is predominantly targeted on mental health problems, post-traumatic stress (PTSD) in particular, with pain rarely addressed as a significant cause of distress and disability. In a systematic review and meta-analysis (Patel, Kellezi and Williams 2014), where we searched for psychological, social or welfare interventions for torture survivors, we found only psychological treatments performed as randomised controlled trials (RCTs). Unfortunately, none of the studies which took a broader approach to rehabilitation, even addressing reparation, and involving survivors as collaborators in designing treatment (a notable example is by Rousseau et al. 2013), was randomised.

Of the nine studies eligible for meta-analysis (Patel, Kellezi and Williams 2014), three were conducted in different African countries, and the remaining six in Europe within refugee and 
torture survivor projects. All targeted PTSD symptom score and/or diagnosis as the primary outcome short and longer term; we were able to analyse depression from two trials, and quality of life from two, the latter only immediately after treatment. The most common treatment, in four trials by the same research group, was narrative exposure therapy (NET), a mixture of testimony as a political and therapeutic act (Cienfuegos and Monelli 1983) and exposure to traumatic events by repeated description in therapeutic sessions (and sometimes recordings of those sessions) (see Grey and Young, 2008; Robjant and Fazel 2010). The remaining four studies of individual therapy used mixed methods: various combinations of Eye Movement Desensitisation (EMDR) that purportedly reassigns traumatic memories to autobiographical memory and in doing so, strips them of their distressing and destabilising intrusive properties (see review by Macfarlane and Kaplan 2012); and cognitive behavioural therapy. One group treatment involved education and reconciliation.

Gains in PTSD and depression were small and only emerged at follow-up, not immediately after treatment, and although effect sizes were moderate and statistically significant, they fell far short of the clinical gains one would hope for. Quality of life was unchanged. There was no consideration of adverse events, despite concerns in the field about the risk of retraumatisation during exposure (Mundt et al. 2014; Robjant and Fazel 2010), and we had considerable doubts about the applicability of assessment instruments and diagnoses developed in wealthy Western countries. These were often (for PTSD) in relation to single traumatic events that interrupted an otherwise stable life, and translated on the spot during the trials. These concerns are described in greater detail in the Cochrane review (Patel, Kellezi and Williams 2014) and in a discussion of the process and findings in the larger context of the needs of torture survivors (Patel, Kellezi and Williams 2016).

\section{Rehabilitation after torture: pain}

Despite the enormously high prevalence of persistent pain in survivors of torture, with many estimates over 80\% (Amris and Williams 2007; Williams, Peña and Rice 2010; Rasmussen 1990), and the widespread use of torture (Amnesty International 2015; Human Rights Watch), recognition of survivors of torture as a group with distinct needs and difficulties is relatively rare in medical writing though commoner in studies of psychological and psychiatric interventions, and in some other non-medical treatments. We were therefore 
not surprised, on systematic search of a wide range of databases and clinical trials registers for any treatment intended to relieve pain or improve functions despite pain, from pharmacotherapy by any route to complementary therapies (Baird et al. 2016), to find very few randomised controlled trials on the treatment of pain in torture survivors.

We did find many hundreds of studies describing the health and wider social and welfare problems of torture survivors, often compounded by being refugees, and by poverty, separation from family and community, and uncertainty of gaining asylum in the host country. Some of these described treatment, even as single case narratives, but many serve to establish the extent of need, to support calls for funding, and to assert human rights in a field in which there is often shame and secrecy.

While the intention of improving services for survivors is an honourable one, these publications may also contribute to pathologising and depoliticising the distress of torture survivors (Pupavac 2006; Summerfield 2001). Presenting individuals as vulnerable and requiring support to adjust to the host country risks focusing attention on refugees' personal and health-related behaviours, and implying that mental health services will largely meet the need. Yet reparation and rehabilitation are rights alongside the right to asylum, albeit far less recognised. We have moved a long way from the presentation as heroic political figures of early cold war refugees such as Solzhenitsyn (Pupavac 2006).

None of the nine studies in the Cochrane review (Patel, Kellezi and Williams 2014) made reference to pain, but a later study by one of the teams included pain as a secondary outcome, described as a 'comorbid' problem of PTSD, along with depression (Neuner et al. 2010). Treatment was NET, directed at reducing PTSD symptoms, and it is not clear whether pain was a significant additional target of treatment for some participants. There is no rationale for expecting NET to improve pain, although it might become less distressing and even less disabling: there are no pain trials using NET from which we can extrapolate.

We found two other studies. One whose results are not yet published except in abstracts and on the project website (DIGNITY 2016) took place in Kosovo, and compares cognitivebehavioural intervention incorporating biofeedback and physical therapy with waiting list control; both groups received multivitamins. Outcomes included psychological symptoms, pain, disability, and physical performance but, according to the website, there was "little difference" in primary outcomes (including pain) followed up for six months, and slightly 
more, but still mostly falling short of statistical significance (and probably also of clinical relevance), in secondary outcomes including disability.

The second (Liedl et al. 2011) was carried out in a treatment centre for torture survivors in Berlin: a three-armed trial, it compared CBT with biofeedback to CBT with biofeedback and physical activity, and to a waiting list. Following psychoeducation about stress, muscle tension and pain, seven of the 10 individual sessions were devoted to biofeedback (using electromyograph (EMG) over the pain site, and heart rate) for relaxation, and one to individual CBT targeting unhelpful thoughts and behaviour associated with pain. The additional physical reactivation component consisted of written instructions for stretch and exercise to be completed daily at home. Pain was unchanged after treatment, but there was some improvement in anxiety and in coping measures, more in the treatment groups than in the waiting list control. Neither EMG nor heart rate changed.

\section{Comments on pain treatment studies}

So we have three rather poor results from these trials. Of the ineligible trials we read as full papers, only a few addressed pain, and none was randomised. The interventions were:

- biofeedback (by the same group as the Liedl et al. 2011 study above: Knaevelsrud et al. 2007; and Muller et al. 2009 retracted);

- acupuncture and Chinese medicine (Highfield et al. 2012);

- pain management rehabilitation (Brodda Jansen et al. 2011).

At first sight, these and the eligible trials appear to be appropriate treatments. Pain management using CBT has been described above (see also Kamper et al. 2014). Education on pain (Phaneth et al. 2014), often a component of pain rehabilitation, sought to normalise and explain pain (as not an ongoing sign of harm), and provided advice on returning to activity: participants scored less pain and disability at the end of treatment, but it is not clear whether only a minority were torture survivors rather than survivors of other violence. Acupuncture and Chinese medicine are both used in the treatment of pain, with modest benefits (e.g. Deare et al. 2013; Vickers et al. 2012; Yuan et al., 2015).

However, the enthusiasm for biofeedback is puzzling, since the muscle tension model of chronic pain that is used in these trials, although popular, has long been disconfirmed, with 
recognition that any benefits from relaxation and biofeedback treatment arise from cognitive change, such as gaining a sense of control (Jensen and Turk 2014); further, dependence on biofeedback equipment to achieve relaxation can produce poor maintenance over the longer term after the equipment is withdrawn (Newton-John, Spence and Schotte 1995). We found no studies of exercise treatments, for which evidence is reasonably strong but in which patients are often unwilling to engage, or the highly credible practice of massage, for which there is little evidence of efficacy (Furlan et al. 2015). Nor did we find a single analgesic trial.

Why are there so few studies of pain interventions with torture survivors? While many may not reach specialist health care or, if they do, may not be recognised as torture survivors (Crosby et al. 2006), there is remarkably little attention to medical interventions, although there are studies of analgesics in refugee camps (e.g. Lacoux and Ford 2002). In treatment offered by the torture survivor projects in the developed and less developed world, but not necessarily represented in the academic literature, treatments for pain appear to be predominantly physical therapy (e.g. Franklin 2001) or complementary and alternative substances and techniques, some of which have no evidence at all of efficacy for chronic pain (such as magnets) (see Sjölund et al. 2009).

In projects where the focus is mental health care, it is not unusual for pain to be subsumed under PTSD as a 'nonspecific' symptom or 'psychosomatic' disorder (e.g. Adams, Gardiner and Assefi 2004), with the assumption that effective mental health treatment will resolve the pain. There is much evidence against this model of pain, and against the expectation that pain will resolve when distress is successfully treated. Beliefs about 'somatisation', applied to health of populations in developed and less developed countries, are not only inappropriate applied to pain, as explained above, but often arise from dualistic concepts and language in Western-developed nosologies and assessment instruments (e.g. Van Ommeren et al. 2001), as well as from cultural idioms with which investigators may be unfamiliar (Williams and Volkmann 2010).

\section{Treating pain in the context of psychological problems}

The multiple theories concerning the association of chronic pain with post-traumatic stress are helpfully reviewed by Bosco, Gallinati and Clark (2013) who examine the processes and models in relation to one another, focusing on fearful maladaptive beliefs and behavioural 
avoidance in both, each maintaining the cycle that restricts activity and exacerbates distress and feelings of helplessness. The relationship between threat and pain is certainly a close one, with some researchers proposing that what is often referred to as the 'pain matrix' in the brain is actually a salience (threat) detection system not specific to pain (Legrain et al. 2011). Bosco, Gallinati and Clark (2013) endorse and describe integrated cognitive behavioural treatment of pain and post-traumatic stress together; using their model requires the caveat that it is based on work in the Veterans' Administration health care provision for traumatised military veterans, a culture where CBT is reasonably familiar.

Reviews of the rehabilitation literature (Sjölund et al. 2009; Jaranson and Quiroga 2011) note the lack of scientifically rigorous studies of multicomponent interventions for torture survivors, and the exclusion in Western countries of refugees from some appropriate services on the grounds of language, culture, or complexity of their psychological and social problems. Jaranson and Quiroga (2011) also ask why there is so little systematic evaluation, or even simple documentation of treatment methods and outcome, of torture survivor services internationally where the model of multidisciplinary treatment has long been established. One might ask, too, why mainstream health services have hosted or produced so few studies, or even case series.

\section{Treating pain in the broader post-torture context}

As we have emphasised already, the torture survivor faces many problems whether he or she remains in the country in which the torture occurred, is a refugee in a neighbouring country, or seeks asylum in an unfamiliar country (see Jaranson and Quiroga 2011). The survivor may be or may feel threatened, suspected and stigmatised; so may his or her family and friends. Refugees face many dangers and difficulties in their journeys and in refugee camps, and often continue to have less than basic shelter, food, and health care.

Even those who are recognised as asylum seekers or even achieve asylum status may be provided with poor accommodation, scant means of support, and may be isolated from others of similar ethnic, language, cultural, political or religious backgrounds; the host community may be indifferent or actively hostile. These conditions adversely affect psychological health (Gorst-Unsworth and Goldenberg 1998). In the UK, Australia, and elsewhere, detention is used punitively as an intended deterrent to others, and conditions in detention often fall short of recognising basic health and wellbeing requirements (Steel et 
al. 2006). Deterioration of psychological health under these conditions is measurable, and there is a very high rate of suicide and attempted suicide in detention (Coffey et al. 2010; Cohen 2008).

Uncertainty about asylum status, about safety and wellbeing of family members left behind or who fled elsewhere, and about possibilities for work and financial independence, exacerbate existing problems. Refugees may have other health problems than pain that require urgent attention. Further, impunity for perpetrators of torture deepens the profound injustice to torture survivors (Basoglu et al. 2005), yet processes of restorative justice and reconciliation can be extremely stressful for torture survivors required to be witnesses, and the legal processes or their outcomes may be far from therapeutic (Avruch 2010; Kagee 2006).

Health care staff should be careful not to make usual assumptions about resources to support treatment (from money for prescriptions to a room large enough to exercise in or sufficiently fluent language to follow written instructions). More importantly, torture survivors face many difficulties and obstacles in establishing their new lives, and pain of clinical concern may not be a priority for survivors. Attempts to treat pain, or intrusions, or other sequelae of torture, without recognising the larger context and being sensitive to how it affects the problem in hand, may well founder.

\section{Clinical implications}

1. Knowing that survivors of torture are often not recognised in clinical settings, health care staff should expect to ask patients and to be able to deal with varied responses, neither forcing disclosure nor feeling overwhelmed by it.

2. For financial reasons, access to interpreters is often restricted, but may be essential. There is no single 'right' way to provide interpretation: patients should be permitted to express a preference for anonymous phone interpretation, professional face to face interpretation, or help from a family member, friend, or community advocate.

3. Pain is taught in much clinician training as a simple symptom of a disorder to be identified, leaving clinicians resorting to lay understanding when no such disorder can be 
found. This is inadequate: assessing and treating pain requires a basic understanding of the biopsychosocial model.

4. Explanation of chronic pain is important and is the basis for discussion of treatment and rehabilitation options. The clinician needs to understand and be able to explain chronic pain, and/or to make use of available good quality materials (see IASP Translated educational resources).

5. Recognition of the often difficult living circumstances of the torture survivor may require flexibility in usual pathways and protocols about attendance and adherence to treatment, although poor adherence may indicate lack of credibility of the treatment to the survivor and require further exploration.

\section{Research implications}

1. Treatment studies for pain from torture need expertise both in pain and in broader rehabilitation of torture survivors. The studies described above appear weak in their understanding of pain and of effective treatment of pain, so that interventions fall short of what could be provided and tested. As in the studies of psychological intervention, researchers' and therapists' preferences and enthusiasms, rather than evidence, often seem to inform design of the trials.

2. Identification of pain mechanisms, including of neuropathic pain components and sensitisation phenomena, should be the basis of evidence-based treatment related to those mechanisms.

3. Common problems after torture, such as foot and leg pain from falanga, requires systematic and standardised examination methods to identify pain mechanisms as a robust basis for treatment studies.

4. Acceptability and utility of clinical testing, such as quantitative sensory testing, need to be examined so that unnecessary exposure to unpleasant procedures is avoided. If required for accurate diagnosis, procedures for explaining and improving acceptability should be developed. 
5. Many standard instruments, such as of quality of life, may not be adequate to quantify problems of torture survivors or desired outcomes. Examination of performance of measuring tools is urgently needed.

6. Treatments should be evaluated not just by pain relief but should aim to improve mood, function, sleep, and other problems identified by the patient and related to the pain (for an overview see IMMPACT website). These should be additional to, not instead of, outcomes identified by torture survivors themselves.

7. Efficacy of pharmacological treatments (including antidepressants and antiepileptic drugs used in pain treatment), after proper assessment, requires auditing to see if the presence of significant psychological distress, at the time of torture and/or at the time of presentation, affects efficacy for pain and related problems.

8. Efficacy of physical and psychological treatments, with an existing evidence base, may require adaptation but should aim at the range of outcomes identified in 6 . There is no reason why these treatments cannot be combined with analgesic interventions.

9. While our review focused on randomised controlled trials, there are important contributions to be made from case series, single case studies, and other methodologies. What is important is that they offer best-evidenced treatment and evaluate with the best possible instruments.

\section{Acknowledgements}

We are grateful to Emma Baird and Leslie Hearn for collaborative work on the Cochrane review of treatment for pain from torture. 


\section{References}

Adams, K.M., Gardiner L.D., and Assefi, N. 2004. "Healthcare Challenges From the Developing World: Post-Immigration Refugee Medicine." British Medical Journal 328: 1548-52.

Amnesty International Report 2014/15: The State of the World's Human Rights https://www.amnesty.org/en/documents/pol10/0001/2015/en/

Amris, K. 2005. "Chronic Pain in Survivors of Torture - Psych Or Soma?" In: Torture and organised violence. Contributions to a professional human rights response, edited by P. Berliner, J. Arenas, and J. Haagensen, 31-69. Copenhagen: Dansk Psykologisk Forlag.

Amris, K., Danneskiold-Samsøe, S., Torp-Pedersen, S., Genefke, I., and Danneskiold-Samsøe, B. 2007. "Producing Medico-Legal Evidence: Documentation of Torture Versus the Saudi Arabian State of Denial." Torture 17: 181-195.

Amris, K., Torp-Pedersen, S., and Rasmussen, O.V. 2009. "Long-Term Consequences of Falanga Torture - What Do We Know and What Do We Need to Know?" Torture 19 (1): 33-40.

Amris, K., and Williams, A. 2007. "Chronic Pain in Survivors of Torture." Pain: Clinical Updates XV: 14. http://www.iasp-pain.org/PublicationsNews/Newsletterlssue.aspx?/temNumber $=2108$ accessed $8^{\text {th }}$ March 2016.

Apkarian, A.V., Hashmi, J.A., and Baliki, M.N. 2011. "Pain and the Brain: Specificity and Plasticity of the Brain in Clinical Chronic Pain." Pain 152: S49-S64.

Arguelles, L. M., Afari, N., Buchwald, D. S., Clauw, D. J., Furner, S., and Goldberg, J. 2006. "A twin study of posttraumatic stress disorder symptoms and chronic widespread pain." Pain 124(1): 150157.

Avruch, K. 2010. "Truth and Reconciliation Processes." Transcultural Psychiatry 47: 33-49. doi: 10.1177/1363461510362043

Baird, E., Williams, A.C. de C., Hearn, L., and Amris, K. 2016. "Interventions for Treating Persistent Pain in Survivors of Torture [Protocol] ." Cochrane Database of Systematic Reviews Issue 1. Art. No.: CD012051. DOI: 10.1002/14651858.CD012051.

Başoğlu, M., Livanou, M., Crnobarić, C., Frančišković, T., Suljić, E., Đurić, D., and Vranešić, M. 2005. "Psychiatric and Cognitive Effects of War in Former Yugoslavia: Association of Lack of Redress for Trauma and Posttraumatic Stress Reactions." Journal of the American Medical Association 294 (5): 580-590.

Blyth, F.M., March, L.M., Nicholas, M.K., and Cousins, M.J. 2005. "Self-Management of Chronic Pain: A Population Study." Pain 113: 85-292.

Bosco, M.A., Gallinati, J.L., and Clark, M.E. 2013. "Conceptualizing and Treating Comorbid Chronic Pain and PTSD." Pain Research and Treatment Article ID 174728. doi. /10.1155/2013/174728

Brodda Jansen, G., Nordemar, R., Larsson, L., and Blyhammar, C. 2011. Abstract: "Pain Rehabilitation for Torture Survivors". European Journal of Pain Supplements $\mathrm{S} 650$.

Bro-Rasmussen, F., and Rasmussen, O.V. 1978. "[Falanga Torture. Are the Sequelae of Falanga Torture Due to the Closed Compartment Syndrome in the Feet and Is This a Common Clinical Picture?]." Ugeskr Laeger 140 (51): 3197-202.

Carinci, A.J., Mehta, P., and Christo, P.J. 2010. "Chronic Pain in Torture Victims." Current Pain and Headache Reports 14: 73-79. DOI 10.1007/s11916-010-0101-2

Cienfuegos, J. and Monelli, C. 1983. "The Testimony of Political Repression as a Therapeutic Instrument." American Journal of Orthopsychiatry 53: 43-51. 
Coffey, G.J., Kaplan, I., Sampson, R.C. and Tucci, M.M., 2010. "The Meaning and Mental Health Consequences of Long-Term Immigration Detention for People Seeking Asylum." Social Science and Medicine 70 (12): 2070-2079.

Cohen, J. 2008. "Safe in Our Hands? A Study of Suicide and Self-Harm in Asylum Seekers." Journal of Forensic and Legal Medicine 15: 235-44.

Crombez, G., Beirens, K., Van Damme, S., Eccleston, C., and Fontaine, J. 2009. "The Unbearable Lightness of Somatisation: A Systematic Review of the Concept of Somatisation in Empirical Studies of Pain." Pain 145: 31-35.

Crosby, S.S., Norredam, M., Paasche-Orlow, M.K., Piwowarczyk, L., Heeren, T. and Grodin, M.A. 2006. "Prevalence of Torture Survivors Among Foreign-Born Patients Presenting To An Urban Ambulatory Care Practice." Journal of General Internal Medicine 21: 784-768.

Deare, J.C., Zheng, Z., Xue, C.C.L., Liu, J.P., Shang, J., Scott, S.W., and Littlejohn, G. 2013.

"Acupuncture for Treating Fibromyalgia." Cochrane Database of Systematic Reviews Issue 5. Art. No.: CD007070. DOI: 10.1002/14651858.CD007070.pub2.

DIGNITY https://www.dignityinstitute.org/what-we-do/urban-violence/projects/randomizedcontrolled-trial-of-treatment-efficacy/accessed $4^{\text {th }}$ March 2016

Dülgeroğlu, D. 2000. "Pathology of the Musculoskeletal System Occurring After Torture." In Annual Report 2000 of Human Rights Foundation of Turkey, 41-47. Ankara: HRFT Publications.

Eccleston, C., Morley, S., and Williams, A. 2013. "Psychological Approaches to Chronic Pain Management: Evidence and Challenges." British Journal of Anaesthesia 111 (1): 59-63.

Edston, E. 2005. "Police Torture in Bangladesh - Allegations By Refugees in Sweden." Torture 15 (1): 16-24.

Edston, E. 2009. "The Epidemiology of Falanga--Incidence Among Swedish Asylum Seekers." Torture 19 (1): 27-32.

Eisenman, D.P., Keller, A.S., and Kim, G. 2000. "Survivors of Torture in a General Medical Setting: How often Have Patients Been Tortured, and How often Is It Missed?" Western Journal of Medicine 172: 301-304.

Engeler, D., Baranowski, A.P., Borovicka, J., Dinis-Oliveira, P., Elneil, S., Hughes, J., Messelink, E.J., and Williams, A.C.D.C. 2015. "Guidelines on chronic pelvic pain 2015." European Association for Urology. Retrieved from https://uroweb.org/guideline/chronic-pelvic-pain/

Franklin, C. 2001. "Physiotherapy With Torture Survivors." Physiotherapy 87 (7):374-7.

Furlan, A.D., Giraldo, M., Baskwill, A., Irvin, E., and Imamura, M. 2015. "Massage for Low-Back Pain." Cochrane Database of Systematic Reviews Issue 9. Art. No.: CD001929. DOI: 10.1002/14651858.CD001929.pub3.

Gorst-Unsworth, C., and Goldenberg, E. 1998. "Psychological Sequelae of Torture and Organised Violence Suffered By Refugees From Iraq. Trauma-Related Factors Compared With Social Factors in Exile." British Journal of Psychiatry 172: 90-4.

Grey, N. and Young, K. 2008. "Cognitive Behaviour Therapy With Refugees and Asylum Seekers Experiencing Traumatic Stress Symptoms." Behavioural and Cognitive Psychotherapy 36 (1): 3-19.

Hadjistavropoulos, T., Craig, K.D., Duck, S., Cano, A.M., Goubert, L., Jackson, P., Mogil, J., et al. 2011. "A Biopsychosocial Formulation of Pain Communication." Psychological Bulletin 137 (6): 910939. doi: 10.1037/a0023876. 
Heapy, A.A., Higgins, D.M., Cervone, D., Wandner, L., Fenton, B.T. and Kerns, R.D. 2015. “A

Systematic Review of Technology-assisted Self-Management Interventions for Chronic Pain." The

Clinical Journal of Pain 31 (6): 470-492.

Highfield, E.S., Lama, P., Grodin, M.A., Kaptchuk, T.J., and Crosby, S.S. 2012. "Acupuncture and Traditional Chinese Medicine for Survivors of Torture and Refugee Trauma: A Descriptive Report." Journal of Immigrant and Minority Health 14: 433-440.

Human Rights Watch www.hrw.org

IASP (International Association for the Study of Pain). Translated educational resources: http://www.iasp-pain.org/education/translatedresources?navltemNumber $=4353$, accessed $8^{\text {th }}$ March 2016.

IASP Recommendations for Pain Treatment Services http://www.iasppain.org/Education/Content.aspx? ItemNumber=1381

IMMPACT (Initiative on Methods, Measurement, and Pain Assessment in Clinical Trials) http://www.immpact.org/

Jaranson, J.M., and Quiroga, J. 2011. "Evaluating the Services of Torture Rehabilitation Programs." Torture 21 (2): 98-140.

Jensen, M.P., and Turk, D.C. 2014. "Contributions of Psychology to the Understanding and Treatment of People With Chronic Pain." American Psychologist 69 (2): 105-118.

Kagee. A. 2006. "The Relationship Between Statement Giving at the South African Truth and Reconciliation Commission and Psychological Distress Among Former Political Detainees." South African Journal of Psychology 36: 10-24.

Kamper, S.J., Apeldoorn, A.T., Chiarotto, A., Smeets, R.J., Ostelo, R.W.J.G., Guzman, J., van Tulder, M.W. 2014. "Multidisciplinary Biopsychosocial Rehabilitation for Chronic Low Back Pain." Cochrane Database of Systematic Reviews Issue 9. Art. No.: CD000963. DOI: 10.1002/14651858.CD000963.pub3.

Knaevelsrud, C., Wagner, B., Karl, A., and Mueller, J. 2007. "New Treatment Approaches: Integrating New Media in the Treatment of War and Torture Victims." Torture 17: 67-78.

Lacoux, P. and Ford, N. 2002. "Treatment of Neuropathic Pain in Sierra Leone." The Lancet Neurology 1 (3)190-: 195.

Legrain, V., lanetti, G.D., Plaghki, L., and Mouraux, A. 2011. "The Pain Matrix Reloaded: A Salience Detection System for the Body." Progress in Neurobiology 93: 111-124.

doi:10.1016/j.pneurobio.2010.10.005

Liedl, A., Muller, J., Morina, N., Anker, K., Denke, C., and Knaevelsrud, C. 2011. "Physical Activity Within a CBT Intervention Improves Coping With Pain in Traumatized Refugees: Results of a Randomized Controlled Design." Pain Medicine 12: 234-45.

Linton, S.J., 2000. “A Review of Psychological Risk Factors in Back and Neck Pain.” Spine 25 (9): 11481156.

McFarlane, C.A. and Kaplan, I. 2012. "Evidence-Based Psychological Interventions for Adult Survivors of Torture and Trauma: A 30 Year Review." Transcultural Psychiatry 49: 539-67.

Merskey, H. 2009. "Somatization: or another God that failed." Pain 145: 4-5.

Merskey, H. and Bogduk, N. (editors). 1994. "Part III: Pain Terms, A Current List with Definitions and Notes on Usage" in Classification of Chronic Pain, Second Edition, IASP Task Force on Taxonomy, IASP Press, Seattle, pp 209-214. http://www.iasp-pain.org/Taxonomy\#Pain 
Moisander, P., and Edston, E. 2003. "Torture and Its Sequel: A Comparison Between Victims From Six Countries." Forensic Science International 137 (2-3): 133-40.

Moreno, A., and Grodin, M. 2002. "Torture and Its Neurological Sequelae." Spinal Cord 40 (5): 21323.

Morville, A.L., Amris, K., Eklund, M., Danneskiold-Samsoe, B., and Erlandsson, L.K. 2014. "A Longitudinal Study of Changes in Asylum Seekers Ability Regarding Activities of Daily Living During Their Stay in the Asylum Center." Journal of Immigrant and Minority Health 17: 852-859. DOI 10.1007/s10903-014-0004-0.

Muller, J., Karl, A., Denke, C., Mathier, F., Dittmann, J., Rohleder, N., and Knaevelsrud, C. 2009. RETRACTED ARTICLE: "Biofeedback for Pain Management in Traumatised Refugees." Cognitive Behaviour Therapy 38 (3): 184-190. DOI: 10.1080/16506070902815024

Mundt, A.P., Wunsch, P., Heinz, A., and Pross, C. 2014. "Evaluating Interventions for Posttraumatic Stress Disorder in Low and Middle Income Countries: Narrative Exposure Therapy." Interventions 12 (2): 250-66.

Musisi, S., Kinyanda, E., Liebling, H., and Mayengo-Kiziri, R. 2000. "Post-Traumatic Torture Disorders in Uganda." Torture 2000;10:81-7.

Nampiaparampil, D.E. 2008. "Prevalence of Chronic Pain After Traumatic Brain Injury." Journal of the American Medical Association 300 (6): 711-719.

Neuner, F., Kurreck, S., Ruf, M., Odenwald, M., Elbert, T., and Schauer, M. 2010. “Can AsylumSeekers With Post-Traumatic Stress Disorder Be Successfully Treated? A Randomized Controlled Pilot Study." Cognitive Behaviour Therapy 39 (2): 81-91.

Newton-John, T.R.O., Spence, S.H., and Schotte, D. 1995. "Cognitive Behavioral Therapy Versus EMG Biofeedback in the Treatment of Chronic Low Back Pain." Behaviour Research and Therapy 33 (6): 691-697.

Norredam, M., Crosby, S., Munarriz, R., Piwowarczyk, L., and Grodin, M. 2005. “Urologic complications of sexual trauma among male survivors of torture. J Urology 65: 28-32.

O'Connor, M. 2009. "Can We Prevent Doctors Being Complicit in Torture? Breaking the Serpent's Egg." Journal of Law and Medicine 17: 426-438.

Olsen, D., Montgomery, E., Carlsson, J., and Foldspang, S. 2006. "Prevalent Pain and Pain Level Among Torture Survivors." Danish Medical Bulletin 53: 210-4.

Olsen, D., Montgomery, E., Bøjholm, S., and Foldspang, S. 2006. "Prevalent Musculoskeletal Pain as a Correlate of Previous Exposure to Torture." Scandinavian Journal of Public Health 34: 496-503.

Olsen, D., Montgomery, E., Bøjholm, S., and Foldspang, S. 2007. "Prevalence of Pain in the Head, Back and Feet in Refugees Previously Exposed to Torture: A Ten-Year Follow-Up Study." Disability and Rehabilitation 29 (2): 163-71.

Patel, N., Kellezi, B., and Williams, A.C. de C. 2014. "Psychological, Social and Welfare Interventions for Psychological Health and Well-Being of Torture Survivors." Cochrane Database of Systematic Reviews Issue 11. Art. No.: CD009317. DOI: 10.1002/14651858.CD009317.pub2.

Patel, N., Kellezi, B., and Williams, A.C. de C. 2016. "Reviewing Outcomes of Psychological Interventions With Torture Survivors: Conceptual, Methodological and Ethical Issues." Torture (in press).

Phaneth, S., Panha, P., Sopheap, T., Harlacher, U. and Polatin, P., 2014. "Education as Treatment for Chronic Pain in Survivors of Torture and Other Violent Events in Cambodia: Experiences With 
Implementation of a Group-Based "Pain School" and Evaluation of Its Effect in a Pilot Study." Journal of Applied Biobehavioral Research, 19(1), 53-69.

Pike, A., Hearn, L., and Williams, A.C. de C. 2016. "Effectiveness of Psychological Interventions for Chronic Pain on Health Care Use and Work Absence: Systematic Review and Meta-Analysis." Pain (in press).

Prip, K., and Persson, A.L. 2008. "Clinical Findings in Men With Chronic Pain After Falanga Torture." Clinical Journal of Pain 24 (2): 135-41.

Prip, K., Persson, A.L., and Sjolund, B.H. 2011. "Self-Reported Activity in Tortured Refugees With Long-Term Sequelae including Pain and the Impact of Foot Pain From Falanga--A Cross-Sectional Study." Disability and Rehabilitation 33 (7): 569-78.

Prip, K., Persson, A.L., and Sjolund, B.H. 2012. "Pain When Walking: Individual Sensory Profiles in the Foot Soles of Torture Victims - A Controlled Study Using Quantitative Sensory Testing." BMC International Health and Human Rights 12: 40. DOI: 10.1186/1472-698X-12-40

Prip, K., Persson, A.L., and Sjolund, B.H. 2012. "Sensory Functions in the Foot Soles in Victims of Generalized Torture, in Victims Also Beaten Under the Feet (Falanga) and in Healthy Controls - A Blinded Study Using Quantitative Sensory Testing." BMC International Health and Human Rights 12: 39. DOI: $10.1186 / 1472-698 X-12-39$

Pupavac, V. "Refugees in the 'Sick Role': Stereotyping Refugees and Eroding Refugee Rights." UNHCR Policy Development and Evaluation Service 2006, New Issues in Refugee Research, Research Paper 128. http://www.unhcr.org/44e198712.pdf

Rasmussen, O.V. 1990. "Medical Aspects of Torture." Danish Medical Bulletin 37: 1-88.

Rasmussen, O.V. 1991. "The Involvement of Medical Doctors in Torture: The State of the Art." Journal of Medical Ethics 17 Suppl: 26-28.

Rasmussen, O., Amris, S., Blaauw, M., and Danielsen, L. 2005. "Medical Physical Examination in Connection With Torture: Section II." Torture 15 (1): 37-45.

Robjant, K., and Fazel, M. 2010. "The Emerging Evidence for Narrative Exposure Therapy: A Review." Clinical Psychology Review 30: 1030-1039.

Savnik, A., Amris, K., Rogind, H., Prip, K., Danneskiold-Samsoe, B., Bojsen-Moller, F., et al. 2000. "MRI of the Plantar Structures of the Foot After Falanga Torture." European Radiology 10 (10): 1655-9.

Sjölund, B.H., Kastrup, M., Montgomery, E., and Persson, A.L. 2009. "Rehabilitating Torture Survivors." Journal of Rehabilitation Medicine 41: 689-96.

Sonntag, S. 2008. “Doctors' Involvement in Torture." Torture 18: 161-175.

Steel, Z., Silove, D., Brooks, R., Momartin, S., Alzuhairi, B., and Susljik, I. 2006. "Impact of Immigration Detention and Temporary Protection on the Mental Health of Refugees." British Journal of Psychiatry 188: 58-64.

Summerfield, D. 2001. "The Invention of Post-Traumatic Stress Disorder and the Social Usefulness of a Psychiatric Category." British Medical Journal 322: 95-98.

Thomsen, A., Eriksen, J., and Schmidt-Nielsen, K. 2000. "Chronic Pain in Torture Survivors." Forensic Science International 108 (3): 155-63.

Torp-Pedersen, S., Amris, K., Holm, C.C., Konig, M., Prip, K., and Danneskiold-Samsoe, B. 2009. "Vascular Response to Ischemia in the Feet of Falanga Torture Victims and Normal Controls - Color and Spectral Doppler Findings." Torture 19 (1): 12-8. 
Tracey, I., and Bushnell, M.C. 2009. "How Neuroimaging Studies Have Challenged Us to Rethink: Is Chronic Pain a Disease?" Journal of Pain 10 (11): 1113-1120.

Turk, D.C., and Okifuji, A.O. 2002. "Psychological Factors in Chronic Pain: Evolution and Revolution." Journal of Consulting and Clinical Psychology 70, 678-690. doi:10.1037/0022-006X.70.3.678

United Nations office of the High Commissioner for Human Rights. 2001. "Istanbul Protocol: Manual on the Effective Investigation and Documentation of Torture and Other Cruel, Inhuman Or Degrading Treatment Or Punishment." Geneva, Switzerland: United Nations.

Van Ommeren, M., de Jong, J.T., Sharma, B., Komproe, I., Thapa, S.B. and Cardena, E., 2001. "Psychiatric Disorders Among Tortured Bhutanese Refugees in Nepal." Archives of General Psychiatry, 58 (5): 475-482.

Vesti, P.B. 1990. "Extreme Man-Made Stress and Anti-Therapy. Doctors as Collaborators in Torture." Danish Medical Bulletin 37: 466-468.

Vickers, A.J., Cronin, A.M., Maschino, A.C., Lewith, G., MacPherson, H., Foster, N.E., Sherman, K.J. et al. 2012. "Acupuncture for Chronic Pain: Individual Patient Data Meta-analysis." Archives of Internal Medicine 172 (19): 1444-1453. doi:10.1001/archinternmed.2012.3654.

Vlaeyen, J.W., and Linton, S.J. 2012. "Fear-Avoidance Model of Chronic Musculoskeletal Pain: 12 Years on." Pain 153 (6): 1144-7.

Wall, P.D. 1999. Pain: the science of suffering. London: Weidenfeld \& Nicolson.

Wang, S.J., Salihu, M., Rushiti, F., Bala, L., and Modvig, J. 2010. "Survivors of the War in the Northern Kosovo: Violence Exposure, Risk Factors and Public Health Effects of An Ethnic Conflict." Conflict and Health 4: 11.

Wang, S.J., Pacolli, S., Rushiti, F., Rexhaj, B., and Modvig, J. 2010. "Survivors of War in the Northern Kosovo (II): Baseline Clinical and Functional Assessment and Lasting Effects on the Health of a Vulnerable Population." Conflict and Health 4: 16. doi: 10.1186/1752-1505-4-16.

Williams, A.C. de C. 2002. "Facial Expression of Pain: An Evolutionary Account." Behavioral and Brain Sciences 25: 439-488.

Williams, A.C. de C. 2016. "What Can Evolutionary Theory Tell Us about Chronic Pain?" Pain (in press).

Williams, A., and Amris, K. 2007. "Pain From Torture." Pain 133 (1-3): 5-8.

Williams, A.C. de C., and Craig, K.D. 2016. "Updating the Definition of Pain." Pain (in press).

Williams, A.C. de C., Eccleston C, Morley S. 2012. "Psychological Therapies for the Management of Chronic Pain (Excluding Headache) in Adults." Cochrane Database of Systematic Reviews Issue 11. Art. No.: CD007407. DOI: 10.1002/14651858.CD007407.pub3.

Williams, A.C. de C., Johnson M. "Debate and Analysis. Persistent Pain: Not a Medically Unexplained Symptom." British Journal of General Practice 2011, 61 (591), 638-639.

Williams, A.C. de C., Peña, C.R., and Rice, A.S.C. 2010. "Persistent Pain in Survivors of Torture: A Cohort Study." Journal of Pain and Symptom Management 40: 715-722.

Williams, A.C. de C., and Volkmann, A.M. 2010. "Understanding Pain From Torture: Cultural Considerations." Journal of Pain Management 3 (4): 359-365.

Woolf, C.J. 2010. “What Is This Thing Called Pain?” Journal of Clinical Investigation 120 (11): 37423744. 
Yuan, Q-L., Guo, T-M., Liu, L., Sun, F., and Zhang, Y-G. 2015. "Traditional Chinese Medicine for Neck Pain and Low Back Pain: A Systematic Review and Meta-Analysis." PLoS ONE 10 (2): e0117146. doi:10.1371/journal.pone.0117146. 